Bayer, Karl, Cristoforo Buondelmonti. Liber insularum archipelagi. Transkription des Exemplars Universitätsund Landesbibliothek Düsseldorf Ms. G 13. Übersetzung und Kommentar

\title{
Emmanuelle Vagnon
}

\section{CpenEdition}

Journals

Édition électronique

URL : http://journals.openedition.org/ifha/1630

DOI : 10.4000/ifha.1630

ISSN : 2198-8943

Éditeur

IFRA - Institut franco-allemand (sciences historiques et sociales)

Référence électronique

Emmanuelle Vagnon, «Bayer, Karl, Cristoforo Buondelmonti. Liber insularum archipelagi. Transkription des Exemplars Universitäts- und Landesbibliothek Düsseldorf Ms. G 13. Übersetzung und Kommentar », Revue de l'IFHA [En ligne], Date de recension, mis en ligne le 01 janvier 2008, consulté le 22 septembre 2020. URL : http://journals.openedition.org/ifha/1630 ; DOI : https://doi.org/10.4000/ifha.1630

Ce document a été généré automatiquement le 22 septembre 2020.

CIFHA 
Bayer, Karl, Cristoforo Buondelmonti. Liber insularum archipelagi. Transkription des Exemplars Universitäts- und Landesbibliothek Düsseldorf Ms. G 13. Übersetzung und Kommentar

Emmanuelle Vagnon 
1 L'ouvrage vient en complément du fac-similé édité par Imgard Siebert et Max Plassmann en 2005 (voir compte rendu ci-dessus). L'introduction historique sur Cristoforo Buondelmonti, la présentation du manuscrit de Düsseldorf et la bibliographie n'y sont pas répétées. On y trouve la transcription de la totalité du texte du Liber insularum avec une traduction en allemand, disposés sur deux colonnes. À la fin de chaque paragraphe sont ajoutées une description sommaire de chaque carte et la transcription des toponymes et des légendes.

2 Les notes sont reportées en fin de volume (p. 61-69) avec un renvoi aux commentaires approfondis du fac-similé pour les plans de Constantinople, Chio, Délos, Caloieros, Cos, Patmos, Gallipoli et le mont Athos. Les notes, claires et utiles, sont néanmoins réduites au minimum linguistique et historique. Il y manque notamment une comparaison avec d'autres recensions du texte.

3 L'index soigné des noms propres est classé en vingt-trois catégories (noms des eaux, des territoires, des villes, des peuples, religion, médecine, botanique, sources littéraires etc.) ; les variantes d'un même nom propre dans le manuscrit et leur traduction moderne sont également fournies. Le livre s'achève sur une carte de situation des îles et sites décrits par Buondelmonti avec une reconstitution de son itinéraire, réel ou fictif, à travers la mer Ionienne, la mer Egée et la mer de Marmara.

Emmanuelle Vagnon (Université Paris I - Panthéon-Sorbonne) 